\title{
Catastrophic health expenditure of cancer patients at the end-of-life: a retrospective observational study in China
}

\author{
Anli Leng ${ }^{1}$, Jun Jing ${ }^{2}$, Stephen Nicholas ${ }^{3,4,5,6^{*}}$ and Jian Wang $^{7^{*}}$ (D)
}

\begin{abstract}
Background: Cancer is the second leading cause of death globally, causing a substantial economic burden on cancer suffers and their families. The aim of this study is to explore the prevalence, determinants and consequences of catastrophic health expenditure (CHE) among urban and rural end-of-life (EOF) cancer patients in China.
\end{abstract}

Methods: Using respondent-driven sampling and face-to-face interviews, field research was conducted with a specialist questionnaire. Data were collected on 792 cancer patients who died between June 2013 and June 2016 in China. The determinants of household catastrophic expenditure were identified by multivariate logistic regression.

Findings: It is found that more than $80 \%$ of cancer patients received life-extending treatment. Extremely high rates of CHE were identified among EOL cancer patients, at $94.3 \%$ for urban families and $96.1 \%$ for rural families. After spending for health, $84.1 \%$ of urban and $91.1 \%$ rural EOL cancer patient households were impoverished, falling below the poverty line. For both urban and rural households, income was the most significant factor associated with catastrophic health expenditure (CHE). Health insurance did not adequately compensate for CHE. Rural families experienced higher $\mathrm{CHE}$, lower levels of health care utilization, a different mix of health care access and higher rates of borrowing for out-of-pocket (OOP) health care expenditures than urban families. Both urban and rural households suffered long-term economic disadvantage due to CHE and borrowing for OOP medical care expenses.

Conclusions: $\mathrm{EOL}$ cancer patients experienced severe $\mathrm{CHE}$, with families forced into poverty. With only about $1 \%$ of EOL cancer patients receiving palliative care, developing palliative care services and expanding the acceptance of palliative care in China is both urgent and essential. To help address impoverishment due to CHE, China should also develop targeted programs to reduce income inequality, especially rural-urban inequalities; increase access to health care; and accelerate health reform. Increasing the retirement age would provide households with more savings and wealth to withstand CHE.

Keywords: Catastrophic health expenditure, Impoverishment, End-of-life, Cancer patients

\footnotetext{
* Correspondence: stephen.nicholas@newcastle.edu.au;

wangjian993@whu.edu.cn

${ }^{3}$ School of Economics and School of Management, Tianjin Normal University,

West Bin Shui Avenue, Tianjin 300074, China

${ }^{7}$ Dong Fureng Institute of Economic and Social Development, Wuhan

University, 54 Dongsi Lishi Hutong, Beijing 100010, China

Full list of author information is available at the end of the article
}

(c) The Author(s). 2019 Open Access This article is distributed under the terms of the Creative Commons Attribution 4.0 International License (http://creativecommons.org/licenses/by/4.0/), which permits unrestricted use, distribution, and reproduction in any medium, provided you give appropriate credit to the original author(s) and the source, provide a link to the Creative Commons license, and indicate if changes were made. The Creative Commons Public Domain Dedication waiver (http://creativecommons.org/publicdomain/zero/1.0/) applies to the data made available in this article, unless otherwise stated. 


\section{Introduction}

Cancer is the leading cause of death in China [1]. The cancer care cost curve displays a distinctive U-shape distribution, with the most resource-intensive stage of health care occurring at the end of life (EOL). The EOL period marks the highest levels of hospital care and the point where medical costs strain family income and household savings the most. For example, one-third of all direct medical costs of cancer treatment in the United States occurred in the final year of life, with approximately $80 \%$ of that expenditure occurring in the last month of care [2]. While cancer care imposes strains on the financial resources of all households, the heavy financial burden during the EOL period means some cancer households incur catastrophic health expenditures (CHE) [3]. How heavy is the economic burden on cancer patients and their families in China? Surprisingly, there are few EOL studies of cancer patients in China, and even fewer studies of CHE. This paper explores the prevalence, determinants and consequences of catastrophic health expenditure among urban and rural cancer patients in China in their last 3 months of life.

Catastrophic health expenditure (CHE) is out-of-pocket (OOP) medical expenses in access of $40 \%$ of household income, after any government health care subsidy, which reduces non-health household expenditure below the level required for necessities [4]. CHE on chronic diseases like cancer [5, 6], diabetes [7], cardiovascular diseases [8], hypertension [9] and mental health [10] means a heavy economic burden on individuals and families, pushing many households into poverty [11-14]. The evidence shows that the economic burden of $\mathrm{CHE}$ was linked to health care utilization [15], especially hospital care $[16,17]$, which was not off-set by health insurance [18-21]. Household economic status was a key determinant of the ability of families to meet OOP expenditures [16, 17, 20]. A study of eight southeast Asia countries found low income category families faced significantly higher odds of catastrophic health expenditure than better off families who had higher wages and larger family financial savings $[15,22]$. The rural-urban income inequality divide also meant rural households will less able to pay for OOP health costs than urban households. For example, Turkish rural households faced a 2.5 times greater exposure to $\mathrm{CHE}$ than urban residents [23].

We expect that cancer-related $\mathrm{CHE}$ to be related to wealth inequalities and the dual urban-rural economic structure in China. China's severe wealth inequalities, with the richest $1 \%$ owning more than $33 \%$ of the total national household wealth, while the poorest $25 \%$ owned less than $2 \%$ of the wealth [23], made poorer Chinese households especially vulnerable to CHE. Further, poor Chinese families were more likely to live in rural areas, and China's dual urban-rural economic structure meant rural households suffered disparities in income, age structure and provision of health care compared to urban households [12, 24]. For example, there were significant urban-rural differences in access to health insurance. Before 2016, the New Rural Cooperative Medical Scheme (NCMS), Medical Insurance for Urban Residents scheme (MIUR) and Medical Insurance for Urban Employees scheme (MIUE) had different deductibles, limit lines and reimbursement rates, with the MIUE offering the highest reimbursement rate (55\%), followed by the MIUR (40\%) and NCMS (30\%) [11].

In this article, we explore the prevalence, determinants and consequences of catastrophic health expenditure (CHE) among urban and rural end-of-life (EOF) cancer patients in China.

\section{Methods}

\section{Study population}

Data are on patients during the last three months of life, who suffered a cancer disease according to the International Statistical Classification of Diseases and Related Health Problems, Tenth Revision (ICD-10), cancer diagnosis codes and had died between June 2013 and June 2016. Drawn mainly from Shandong (47.6\%), Shan'xi (11.24\%), Yunnan (9.47\%), Jiangxi 7.83\%), Henan (5.30\%), Anhui (4.92) provinces, with the remainder other provinces, autonomous regions and municipalities (13.64\%), the sample comprised 792 advanced cancer patients, suffering from five main types of cancer: lung, intestinal, gastric, liver, and esophagus cancer.

\section{Data collection}

Deceased cancer patients are an archetypical hidden population, and families of deceased cancer were also a hard-to-reach population, especially given China's social norms that made families reluctant to publicly acknowledge their relatives' cancer status. Alternative data on deceased cancer patients, such as hospital and insurance records, were strictly limited by confidentiality and privacy. To sample such a hard-to-reach population, we used respondent-driven sampling (RDS), which uses social chain referrals in the target population's social network to collect personal health related data [25-28].

Twenty field research trained medical students sought support from the health care professionals in provincial health care facilities to establish contact with caregivers and relatives of deceased cancer patients. Based on the demographic characteristics of the population-based cancer deaths in China, 12 rural and 8 urban "seeds" of the target population comprised wave 1 of a rigorous chain recruitment process, where seeds were given coupons to recruit success waves of respondents [25-27] Providing unbiased population estimates [25-27], RDS 
mitigates bias in the sample's socio-demographic characteristics, by recruiting caregivers of deceased cancer patients reflecting the urban and rural location and different socio-economic backgrounds, marital status and ages of China's population-wide deceased cancer patients. All surveys were conducted face-to-face, where the primary caregiver was asked detailed questions about the deceased cancer patients and coupons were used to gain referrals to other caregivers, who can remain anonymous, if desired [29]. Data collection continued for two months, with a maximum chain length of six waves, allowing an equilibrium sample size on the key variables to be achieved. Previous studies reported that valid and representative samples could be obtained by six or more RDS waves [28]. Importantly, we found no statistically significant differences in socio-demographic characteristics between our sample and population-based cancer deaths in China [30-32].

The deceased patient's demographic characteristics, health services utilization and EOL out-of-pocket payments were included in the questionnaire. The interviews provided a retrospective database, including health service expenses related to the patient's cancer treatment and related health cost issues. While one challenge of retrospective surveys is recall bias, there are a number of reasons for confidence in our data, especially the accuracy of the health care expenditure information. Reimbursement procedures were complex, with patients and their carers paying medical expenses before seeking reimbursement from their medical insurance, which meant medical expenses were recalled from the initial payment, then again as part of the health insurance claims. Medical insurance claim forms required accurate information. Second, OOP expenses accounted for a significant proportion of family income and savings, and these large demands on savings and income would have been a matter of ongoing and constant concern. Frequently, family and friends were called on for loans to pay for the cancer patient's medical costs, another reason to be confident that the medical costs were accurate recalled. The interviewers were trained to prompt interviewees to carefully recollect medical expenses. When caregivers were uncertain about OOP expenses, additional information was sought from the patient's family doctor and, when available, patients' medical records were used to identify some medical costs and invoices were used to calculate expenses.

\section{Key variables}

Our data comprised information on the patient's gender, age, marital status, residence, occupation status, monthly household income and expenditures, health insurance status, cancer site and health care utilization, including impatient and outpatient care. Catastrophic health expenditure was defined as OOP health payments exceeding $40 \%$ of a household's income [11]. The impoverishment rate referred to whether OOP cancer health-care payments caused the household to drop below the poverty line [33]. Rural poverty was defined by the State Council Leading Group Office of Poverty Alleviation and Development in China as below RMB2300 per capita annual income [34]. There is no unified national urban poverty line. To measure urban poverty, we used a urban poverty line calculated by Chen et al. which was RMB4500 per capita annual income [35].

\section{Statistical analysis}

The proportion of households with catastrophic medical expenditure and the household impoverishment rate were calculated. Descriptive statistics were used to compare the distribution of patient social-demographic characteristics, health care utilization and OOP expenditure at the end of life by gender and geographic locations. Logistic regression was used to analyze the determinants of catastrophic health expenditure [33]. All costs were adjusted to 2016 prices. The analyses were conducted using STATA, version 14 and significance was assessed at level of 0.05 .

\section{Results}

\section{Characteristics of the study population}

Table 1 presents the distribution of social-demographic characteristics of EOL cancer patients between urban and rural areas. There were no significant urban-rural differences by age (about $50 \%$ were over 65 ) and marital status (roughly $80 \%$ married). However, there were important urban-rural differences: compared with urban patients, rural patients were more likely to be male, less likely to have steady work and more likely to have a shorter survival time from diagnosis to death. The main insurance plan of rural patients was NUMS, while urban patients were insured mainly under the MIUE.

\section{Distribution of household income quintile by rural and urban areas}

Table 2 shows the quintile distribution of household income by rural and urban areas. We divided urban and rural patients into five income groups based on the monthly household income, ranging from the poorest (1st quintile) to the richest (5th quintile) households. The average household income in urban areas was roughly three times that of rural areas.

\section{Health care services utilization}

Figure 1 presents urban-rural disparities in health care utilization by income quintiles. Rural patients at the end-of-life were significantly less likely to access inpatient care than urban patients, who had high inpatient care rates across all income quintiles. Rural patients 
Table 1 Characteristics of the study sample by geographical location ( $N=792$ )

\begin{tabular}{|c|c|c|c|c|c|c|c|}
\hline \multirow[t]{2}{*}{ Characteristics } & \multicolumn{3}{|c|}{$\begin{array}{l}\text { Urban area } \\
(n=195)\end{array}$} & \multicolumn{3}{|c|}{$\begin{array}{l}\text { Rural area } \\
(n=597)\end{array}$} & \multirow[t]{2}{*}{$p$ value* } \\
\hline & $\bar{N}$ & $\%$ & Mean & $\mathrm{n}$ & $\%$ & Mean & \\
\hline Gender & & & NA & & & NA & 0.003 \\
\hline Male & 116 & 59.49 & & 423 & 70.85 & & \\
\hline Female & 79 & 40.51 & & 174 & 29.15 & & \\
\hline Age & & & 64.75 & & & 64.01 & 0.588 \\
\hline Age $<45$ & 15 & 7.69 & & 44 & 7.49 & & \\
\hline Age 45-55 & 37 & 18.97 & & 77 & 13.12 & & \\
\hline Age 55-65 & 40 & 20.51 & & 174 & 29.64 & & \\
\hline Age $65-75$ & 48 & 24.62 & & 169 & 28.79 & & \\
\hline Age $\geq 75$ & 55 & 28.21 & & 133 & 22.66 & & \\
\hline \multicolumn{8}{|l|}{ Marriages } \\
\hline Unmarried & 39 & 20.00 & & 96 & 16.08 & & 0.206 \\
\hline Married & 156 & 80.00 & & 501 & 83.92 & & \\
\hline Occupation & & & & & & & 0.000 \\
\hline Farmer & 37 & 18.97 & & 476 & 79.73 & & \\
\hline Steady workers & 27 & 13.85 & & 42 & 7.04 & & \\
\hline $\begin{array}{l}\text { Non-regular } \\
\text { workers }\end{array}$ & 55 & 28.21 & & 55 & 9.21 & & \\
\hline The retired & 76 & 38.97 & & 24 & 4.02 & & \\
\hline Insurance status & & & & & & & 0.000 \\
\hline MIUE & 92 & 47.18 & & 37 & 6.20 & & \\
\hline MIUR & 28 & 14.36 & & 37 & 6.20 & & \\
\hline NUMS & 37 & 18.97 & & 473 & 79.23 & & \\
\hline $\begin{array}{l}\text { Other insurance } \\
\text { plan }\end{array}$ & 30 & 15.39 & & 21 & 3.52 & & \\
\hline None & 8 & 4.10 & & 29 & 4.85 & & \\
\hline $\begin{array}{l}\text { Days from diagnosis } \\
\text { to death }\end{array}$ & & & 548.82 & & & 448.29 & 0.000 \\
\hline$\leq 3$ months & 35 & 17.95 & & 96 & 16.08 & & \\
\hline $\begin{array}{l}3 \text { months- } 6 \\
\text { months }\end{array}$ & 33 & 16.92 & & 123 & 20.60 & & \\
\hline 6 months- 1 year & 57 & 29.23 & & 157 & 26.30 & & \\
\hline 1 year- 2 years & 40 & 20.51 & & 137 & 22.95 & & \\
\hline$\geq 2$ years & 30 & 15.38 & & 84 & 14.07 & & \\
\hline Cancer site & & & & & & & 0.000 \\
\hline Lung & 42 & 21.54 & & 145 & 24.29 & & \\
\hline Intestinal & 18 & 9.23 & & 35 & 5.86 & & \\
\hline Gastric & 27 & 13.85 & & 99 & 16.58 & & \\
\hline Liver & 30 & 15.38 & & 105 & 17.59 & & \\
\hline Esophagus cancer & 8 & 4.1 & & 78 & 13.07 & & \\
\hline Other & 70 & 35.9 & & 135 & 22.61 & & \\
\hline
\end{tabular}

* $p$-value from Chi-squared test or T-tests were also more likely to mix outpatient and inpatient care compared to EOL urban patients who overwhelmingly opted for only inpatient care. Patients in the lowest two rural income quintile were the least likely to access health care (about 20\%); the least likely to access inpatient care (about 35\%); and the most likely to use only outpatient services (about 15\%) compared to all the other income quintile. Among 792 decedents, only 9 (1.14\%) cancer patients received hospital palliative care at the end of life, of which 4 were urban cancer patients and 5 rural patients.

\section{EOL health expenditure and out-of-pocket expenditure by quintile}

Figure 2 reports that the average EOL health expenditure and EOL out-of-pocket expenditure of urban cancer patients were about two times that of rural patients. But calculating the share of monthly health expenditure and OOP expenditure in family income, rural patients allocated a higher proportion of household income to health care and to OOP expenditures. The proportion of family income allocated to health expenditures and OOP expenses was higher for low income quintiles than for high income quintiles.

\section{Catastrophic health expenditure by quintile}

Table 3 shows that $94.3 \%$ of urban households and $96.1 \%$ of rural households spent $40 \%$ or more of their monthly income as out-of-pocket cancer health care expenditure, signaling very high levels of $\mathrm{CHE}$ at the end of life. The poorer the household, the higher the prevalence of catastrophic health expenditure. OOP payments were about 24 times household income in the urban poorest income quintile, reaching up to about 36 times household income in the lowest rural income quintile.

\section{Poverty levels and impoverishment}

Before any out-of-pocket health care expenditures, poor households accounted for $10.8 \%$ of all urban households. But $50 \%$ of urban households in the lowest quintile fell below the poverty line. (see Fig. 3). In rural areas, poor households accounted for $25.3 \%$ of all rural households. But $90 \%$ of rural households in the first quintile and $17.2 \%$ in the second quintile fell below the poverty line. After OOP spending for EOL cancer care, $84.1 \%$ of all urban households and $91.1 \%$ of all rural households became impoverished, falling below the urban or rural poverty line. Impoverished households comprised $100 \%$ in the first income quintile, irrespective of urban or rural location. 
Table 2 Distribution of household income quintile by rural and urban areas ( $\mathrm{N}=792)$

\begin{tabular}{|c|c|c|c|c|c|c|}
\hline \multirow{2}{*}{$\begin{array}{l}\text { Monthly } \\
\text { household } \\
\text { income }\end{array}$} & \multicolumn{3}{|c|}{ Urban area $(n=195)$} & \multicolumn{3}{|c|}{ Rural area $(n=597)$} \\
\hline & $\bar{N}$ & $\%$ & Mean (US\$ $\left.\$^{b}\right)$ & $\bar{n}$ & $\%$ & Mean (US\$) \\
\hline Quintile $1^{a}$ & 42 & 21.54 & 88.45 & 150 & 25.13 & 29.73 \\
\hline Quintile 2 & 40 & 20.51 & 287.30 & 93 & 15.58 & 75.75 \\
\hline Quintile 3 & 35 & 17.95 & 524.24 & 125 & 20.94 & 142.87 \\
\hline Quintile 4 & 44 & 22.56 & 882.49 & 112 & 18.76 & 276.85 \\
\hline Quintile 5 & 34 & 17.44 & 2127.63 & 117 & 19.60 & 879.69 \\
\hline Total & 195 & 100.00 & 742.17 & 597 & 100.00 & 273.52 \\
\hline
\end{tabular}

US\$ United States dollars

${ }^{a}$ Quintile 1 is the poorest and quintile 5 is the wealthiest

${ }^{b}$ Based on a currency exchange rate of the 6.6423 yuan to US\$1.00 in 2016

\section{Borrowing money to undertake the catastrophic out-of- pocket payments}

Figure 4 reveals that 254 households, roughly one-third of the sample, borrowed money from their relatives and friends to meet cancer-related EOL medical costs. Irrespective of urban-rural location, the largest amounts of money borrowed, roughly US\$10000, were by the poorest income quintile households, followed by the richest income quintile households. The average repay time was inversely related to the income quintiles, and much longer for rural households than urban households.

\section{Determinants of catastrophic health expenditure}

Table 4 presents estimates of the determinants of catastrophic health expenditure. Household income was the most significant factor associated with catastrophic health expenditure. Households with higher income were less likely to incur catastrophic health expenditure no matter their urban or rural location. In contrast to urban households, rural patients receiving inpatient services and outpatient services significantly increased their risk of catastrophic out of pocket expenses.

\section{Discussion}

Our study found that out-of-pocket payments for EOL cancer patients meant $94.3 \%$ of urban and $96.1 \%$ of rural patients incurred CHE. These proportions are much higher than that reported in other countries, with $\mathrm{CHE}$ rates significantly lower in Malaysia (47.8\%) [32], South Korea (39.8\%) [36], Iran (67.9\%) [6] and eight Southeast Asian countries (48\%) [15]. Even more concerning, 84.10\% urban EOL cancer households and $91.10 \%$ rural EOL cancer households in China dropped below the poverty line after out-of-pocket payments. These rates of EOL cancer patient impoverishment contrast with $7.5 \%$ of all Chinese households (not EOL cancer households) officially in poverty in the Fourth National Health Service Survey [11]. In China, out-of-pocket payments of EOL cancer patients brought impoverishment to a significant proportion of lower income families, especially rural households, and imposed a serious economic burden to most households irrespective of income or urban-rural location.

The key role of household income in catastrophic health expenditure was consistent with studies in other countries [13, 17, 20, 32]. In China, poor households and rural households were the most likely to face impoverishment and economic hardship. Income inequality exacerbated the hardships of catastrophic out-of-pocket payments. As shown in Table 3, the share of catastrophic OOP payments in household income in the poorest quintile was about 17 times that in the richest quintile in rural areas and 24 times that in urban area. To pay for catastrophic OOP expenditures, families, especially in the lower income quintiles, borrowed from their relatives and friends, with poorer household requiring more time for loan repayments than richer households. With between two and five years required for loan repayment, $\mathrm{CHE}$ not only pushed families into poverty, but created a long-term household economic burden.

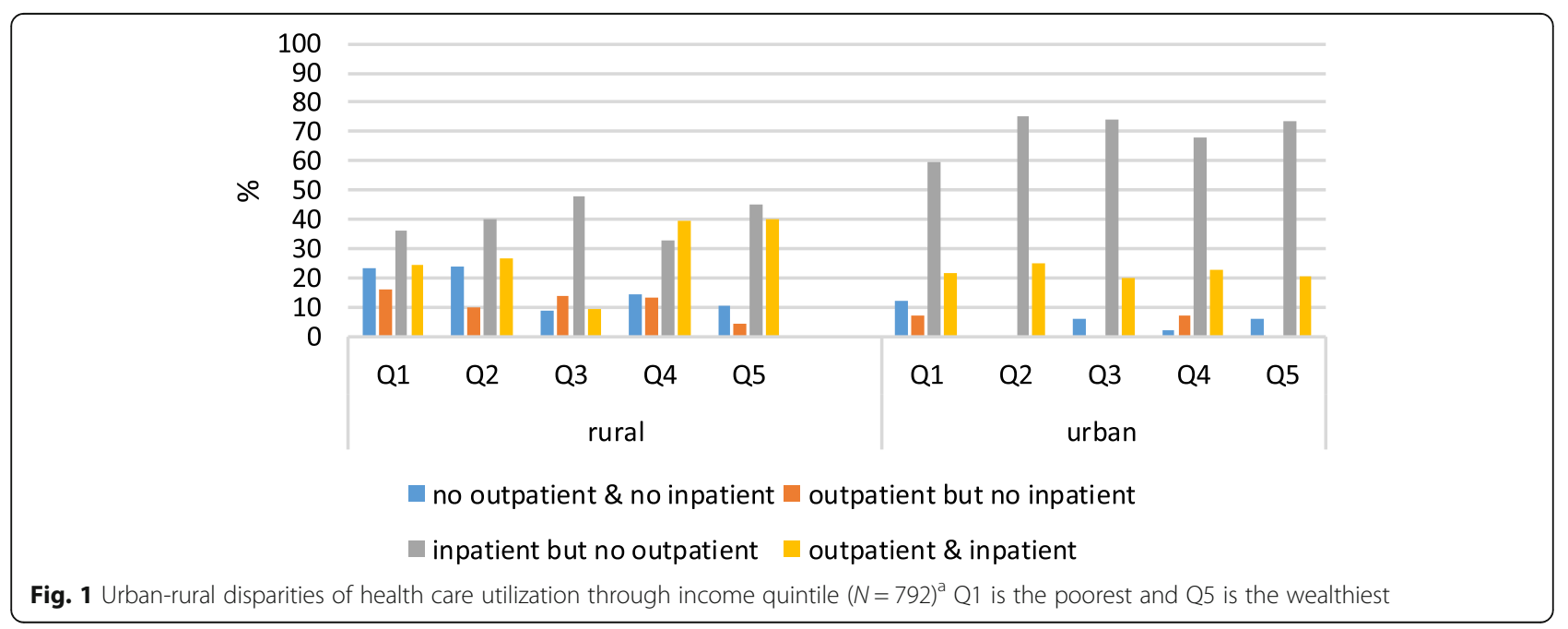




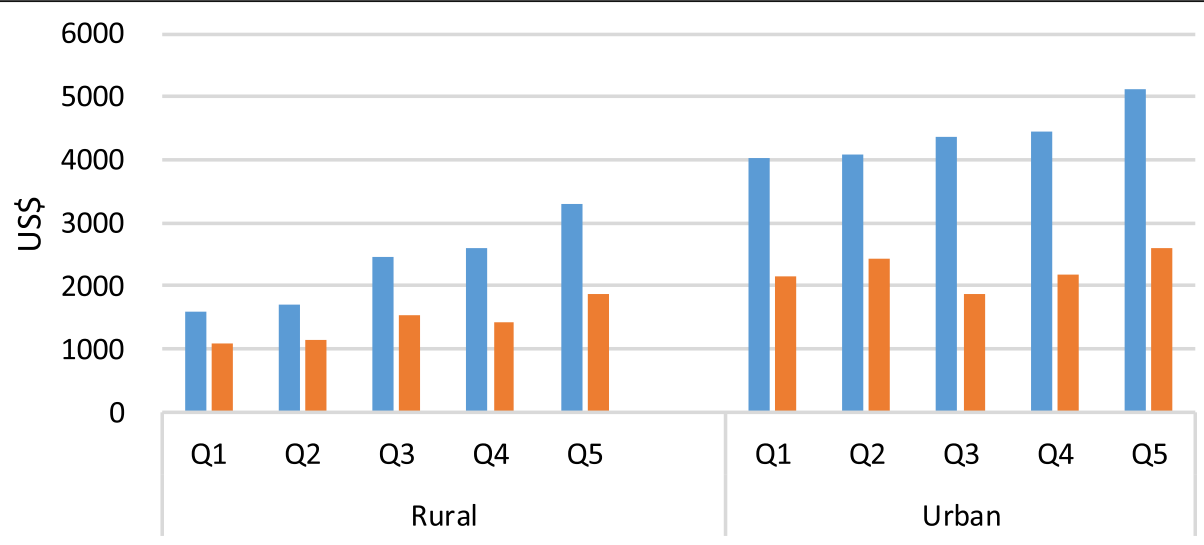

Average monthly health expenditure Average monthly out-of-pocket payments

Fig. 2 Monthly health expenditure and out-of-pocket payments through income quintile ( $N=792)$ US\$, United States dollars. ${ }^{\text {a }}$ Q1 is the poorest and Q5 is the wealthiest. ${ }^{b}$ Based on a currency exchange rate of the 6.6423 yuan to US\$1.00 in 2016

We also found the health care utilization was another determinant of CHE for EOL cancer patients, especially in rural households, which is also consistent with other studies $[15,16]$. Rural patients were more likely to be outpatients, while urban patients were more likely to be inpatients. This reflected, in part, rural-urban differences in inpatient and outpatient care, with rural patients accessing village and township clinics and county hospitals, while urban patients accessed city and provincial hospitals. Our sample did not contain observations from remote areas, with both rural and urban patients in our sample accessing health facilities within $5 \mathrm{~km}$ of their home [37]. Households with hospitalized patients were 12.8 times more likely to incur catastrophic health expenditure than households with outpatient care; households accessing outpatient care were 3.1 times more likely to incur CHE than patients not accessing health care. Potential OOP expenditure may have discouraged inpatient care and encouraged patients to seek either outpatient care or no health care.

Health care insurance had a limited impact on OOP health care expenditures. The average insurance reimbursement rate for cancer patients was only $40 \%$ in rural households and $54 \%$ in urban households, which helps explain why health insurance was not a significant factor explain CHE in our study. Further, the urban-rural differences in NCMS, MIUE and MIUR reimbursement rates meant insured rural household bore higher out-of-pocket expenditures than insured urban households, which imposed a higher economic burden on rural families and reduced their access to health care facilities relative to urban households. For example, the poorest households in the rural area suffered the most severe economic burden. The out-of-pocket EOL cancer care expenses were about 36 times rural household income, incurring borrowings of up US $\$ 10,000$ from their relatives and friends, with about a five year pay-back period.

While the urban-rural rates of catastrophic health expenditure were not significantly different from each other, they were both extremely high. Further, catastrophic out-of-pocket payments by EOL cancer patients imposed a much higher economic burden on rural than urban households. The poorest households suffered a greater economic burden than rich families from CHE, and rural households suffered greater OOP expenses, and a more severe economic burden, than urban families.

Table 3 Urban-rural disparities of the prevalence of catastrophic health expenditure through income quintile $(N=792)$

\begin{tabular}{|c|c|c|c|c|c|c|c|c|c|c|c|c|c|}
\hline \multirow[t]{2}{*}{ Variable } & \multicolumn{6}{|c|}{ Rural $(n=597)$} & \multicolumn{6}{|c|}{ Urban $(n=195)$} & \multirow[t]{2}{*}{$p$ value ${ }^{*}$} \\
\hline & $\overline{\mathrm{Q} 1}$ & Q2 & Q3 & Q4 & Q5 & total & $\overline{\mathrm{Q} 1}$ & Q2 & Q3 & Q4 & Q5 & total & \\
\hline $\begin{array}{l}\mathrm{OOP} \text { payments share in total } \\
\text { health expenditure (\%) }\end{array}$ & 68.09 & 68.82 & 62.27 & 54.75 & 56.94 & 60.72 & 53.21 & 43.33 & 42.74 & 49.13 & 42.48 & 46.39 & 0.000 \\
\hline $\begin{array}{l}\text { OOP payments share in } \\
\text { household income (\%) }\end{array}$ & 3635.62 & 1500.00 & 1069.38 & 513.19 & 214.20 & 513.41 & 2423.21 & 614.95 & 356.78 & 248.08 & 102.25 & 273.92 & 0.000 \\
\hline $\begin{array}{l}\text { Households with catastrophic } \\
\text { health expenditure (\%) }\end{array}$ & 100 & 100 & 98.40 & 94.60 & 87.20 & 96.10 & 100 & 100 & 100 & 95.50 & 73.50 & 94.30 & 0.285 \\
\hline
\end{tabular}

${ }^{\mathrm{a}} \mathrm{Q} 1$ is the poorest and Q5 is the wealthiest

* $\mathrm{p}$-value from Chi-squared test 


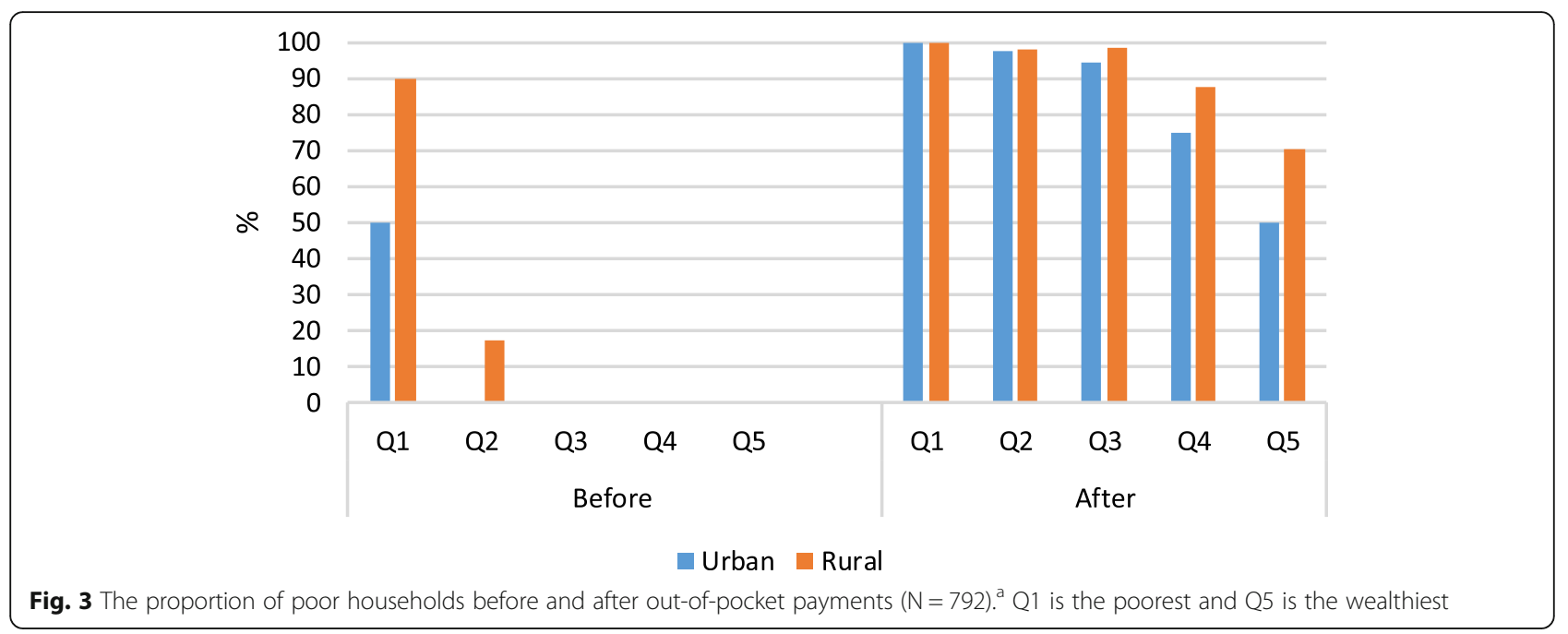

Addressing the CHE challenges to families requires an equitable, affordable and cost-effective people-centered health care system, dependent on deepening health care reform in China [38]. Healthy China 2030 outlines an ambitious reform program, including universal health insurance coverage, a national essential medicines system, improvements in the primary care system, equitable public health services access and public hospital reform [39]. Enhancing China's primary health-care system and reform of public hospitals will both reduce medical costs and improve equity and access to health care. These reforms are particularly urgent for rural patients. Expanding the scope and depth of health insurance and reducing the co-payment for inpatient services provides a direct way to reduce the out-of-pocket medical payments. Healthy China 2030 identifies the need to develop a multi-tiered medical insurance system, with basic medical insurance as the main body, but various other forms of supplementary insurance and commercial health insurance as supplements [39]. Catastrophic health insurance would provide a supplementary health insurance plan, but it would need to be structured to ensure widespread availability, especially to poorer and rural families.

We also recommend investing in palliative care facilities. We found that among 792 decedents, only $1.14 \%$ of cancer patients received hospital palliative care at the end of life. The proportion of cancer patients receiving palliative care in the United States was about 40 times greater than in China, where about $46 \%$ patients received at least one-day

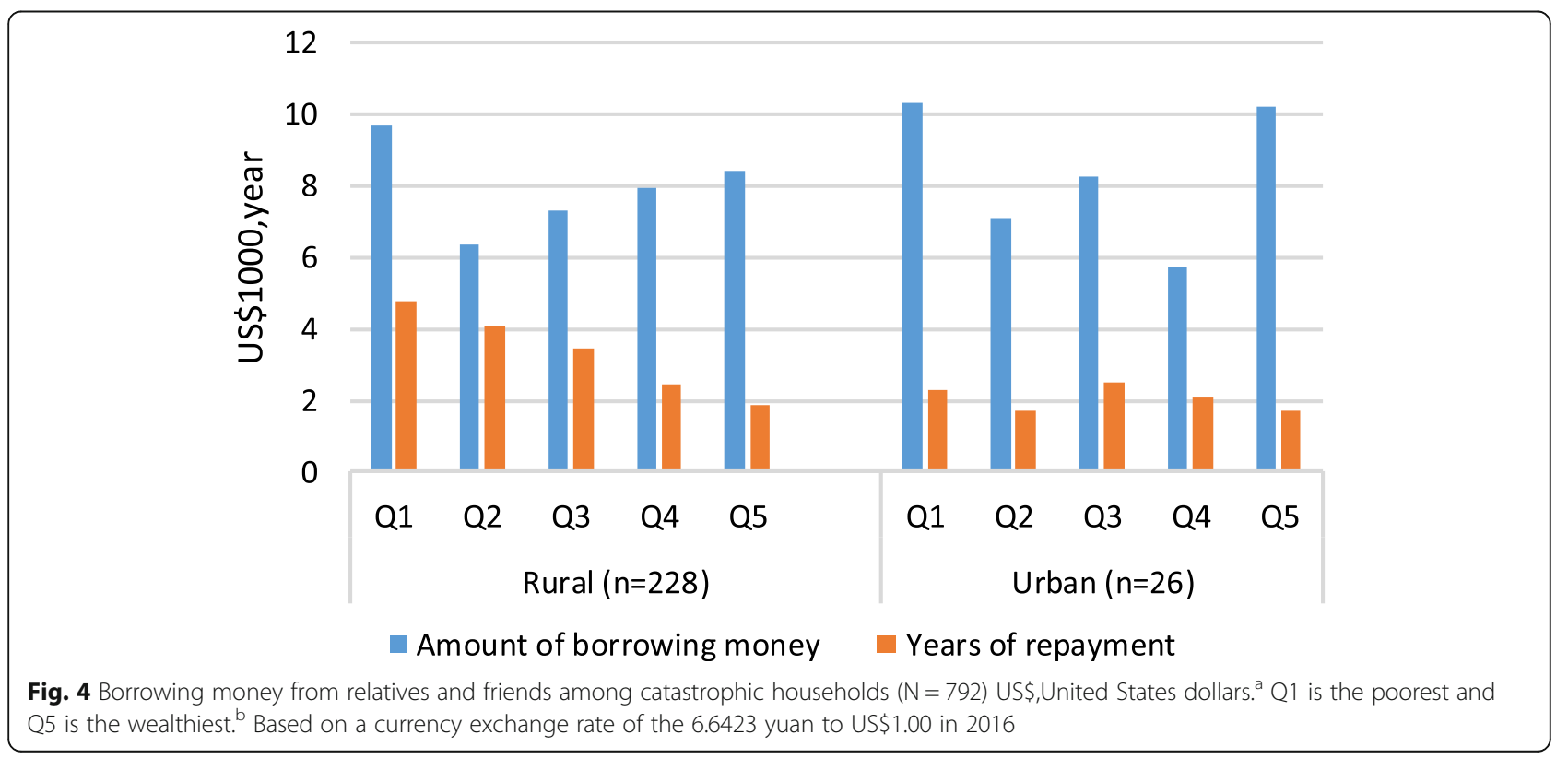


Table 4 Determinants of catastrophic health expenditure in logistic regression model $(N=792)$

\begin{tabular}{|c|c|c|c|c|c|c|}
\hline \multirow[t]{2}{*}{ Variable } & \multicolumn{3}{|c|}{ Urban } & \multicolumn{3}{|l|}{ Rural } \\
\hline & $\mathrm{OR}$ & $95 \% \mathrm{Cl}$ & $p$ value & $\mathrm{OR}$ & $95 \% \mathrm{Cl}$ & $p$ value* $^{*}$ \\
\hline Age & 3.09 & $0.43-22.47$ & 0.264 & 0.66 & $0.24-1.84$ & 0.431 \\
\hline Gender & 1.11 & $0.18-6.92$ & 0.910 & 1.19 & $0.38-3.74$ & 0.765 \\
\hline Monthly household income & 0.12 & $0.03-0.55$ & 0.006 & 0.24 & $0.12-0.46$ & 0.000 \\
\hline Days from diagnosis to death & 0.60 & $0.29-1.22$ & 0.159 & 1.04 & $0.67-1.62$ & 0.857 \\
\hline Inpatient & 0.33 & $0.02-6.93$ & 0.478 & 12.82 & $4.29-38.32$ & 0.000 \\
\hline Outpatient & 1.23 & $0.17-8.72$ & 0.834 & 3.11 & $1.00-9.64$ & 0.049 \\
\hline Insurance & 0.83 & $0.47-1.46$ & 0.523 & 1.04 & $0.72-1.52$ & 0.822 \\
\hline
\end{tabular}

*p-value from logistic regression model

palliative care [40]. Poorly serviced by palliative care, which provides patients with alternative medical treatment choices, Government action is required to increase the size of palliative medicine-trained workforce and promote optimal mixes of public-private palliative care, especially for poorer rural communities. Besides investing in palliative care facilities, there are additional challenges facing palliative care in China. First, there is a long way to go for improving the acceptance and popularity of palliative care. Second, the insurance schemes need to provide adequate reimbursement for palliative care, which will also be conducive to improve the acceptance of palliative care. Finally, adequate education and perception of palliative care as end-of-life care should be promoted [1].

More generally, educating EOL patients on making appropriate health care choices would help to avoid overtreatment, especially reducing inpatient care for urban patients. It is unclear how families make EOL treatment decisions, and we speculate that treatment choices will vary between rural and more traditional family value families and urban families. Education and training will also help health care professionals to identify patients who should not receive treatment or receive outpatient rather than inpatient treatment or be directed to palliative care. Therefore, education programs that seek to change culture-based decision-making by EOL patients, EOL patients' families and health professionals need to be modeled for different cultural and urban-rural groups in China.

Considering that average age of EOL cancer patients in our study was about 64 years old, encouraging longer periods of work would improve the ability to pay OOP catastrophic health costs. By international standards, China's retirement age is low, on average 60 years old for men and 55 for women. With China's aging population, postponing retirement ages will enhance the earning capacity and wealth of families, and also ease the old-age burden on the medical system. Further, government promoted labor income plans at the province, city and county level, such as organizing farmers to seek non-agricultural work and enter business, might be extended to medical assistance programs to cover out-of-pocket payments, especially for rural households. Finally, social security schemes and poverty alleviation programs could be accelerated to lift families out of poverty, caused by CHE [41].

\section{Limitations}

There are a number of limitations in our study. First, we obtained OOP expenses through retrospective data reported by the caregivers. In spite of impact on family income and savings of OOP expenses, their payment to hospitals before being reclaimed as part of insurance reimbursements, the borrowing from relatives and friends to cover medical expenses by many families and the training of interviewers to prompt accurate information, some OOP cost data might be missing or inaccurate. Second, we calculate the impoverishment of households based on their current income, not household savings and wealth. This could overestimate the proportion of families impoverished by CHE. However, when out-of-pocket payments are financed by savings, depleting household assets, households are vulnerable to future shocks on household resources and to future impoverishment. Our study found that borrowing to pay for OOP medical expenses put households at risk, imposing a long-term financial burden. Third, we only analyze the out-of-pocket spending of EOL cancer patients. If there are other family member suffering chronic diseases, the proportion of households facing catastrophic health expenditure might be higher than that in our study. These limitations need to be taken into consideration in further studies, including collecting additional data on treatment days, hospital stays and cancer stages.

\section{Conclusions}

Out-of-pocket health payments of EOL cancer patients were financially catastrophic for most rural and urban households, pushing families into poverty. The economic status of households and their health care utilization were significant factors associated with the CHE. Lower income and rural EOL cancer patients experienced severe $\mathrm{CHE}$, with households forced into poverty. To 
address CHE, the government must improve the development of palliative care services and expand the acceptance of palliative care. In addition, accelerating health reform, educating medical professionals to offer and patients to understand alternative EOL medical treatment programs is vital. Providing a range of supplementary health insurance options, especially increasing adequate reimbursement for catastrophic health insurance and establish institutions to provide palliative care services, would provide vulnerable families a safety net during catastrophic illnesses. There were significant differences in rural-urban health care access, health insurance rebates and income levels that influenced the likelihood of impoverishment for households facing CHE. Better targeted programs to deal with rural poverty and income inequalities are required. Increasing the retirement age would help address savings and wealth levels of rural and poor urban households.

\section{Abbreviations}

CHE: Catastrophic Health Expenditure; EOF: End-of-life; ICD-10: the International Statistical Classification of Diseases and Related Health Problems Tenth Revision; MIUE: Medical Insurance for Urban Employees Scheme; MIUR: Medical Insurance for Urban Residents Scheme; NCMS: New Rural Cooperative Medical Scheme: OOP: Out-of-pocket; RDS: Respondent-driven sampling

\section{Acknowledgments}

The authors are grateful to medical students in Shandong University, for their assistance in collecting data. The authors thank the editor and reviewers for suggestions that have significantly improved the paper.

\section{Funding}

This work was supported in part by grants from the National Natural Science Foundation of China (Project no. 71702131 and 71373146), and China Scholarship Council in 2017 (File No. 201706220244). The contents of this publication are solely the responsibility of the authors.

\section{Availability of data and materials}

The dataset supporting the conclusions of this article is available from the corresponding author on reasonable request.

\section{Authors' contributions}

JW and JJ contributed towards the article by making substantial contributions to conception and design. AL contributed towards the article by collecting data and undertaking the statistical analysis, interpretation of the data, and writing the manuscript. SN engaged in interpreting the results and writing the paper. All authors read and approved the final version of the manuscript.

\section{Ethics approval and consent to participate}

Participants were informed that they could refuse to answer any question. The questionnaire did not ask about infection status, and no biological samples were collected. The consent obtained from participants was written. The project was approved by the Medical Ethics Committee at the Shandong University School of Medicine (Grant No. 201001052).

\section{Consent for publication}

Not applicable.

\section{Competing interests}

None of the authors has any conflicts of interest.

\section{Publisher's Note}

Springer Nature remains neutral with regard to jurisdictional claims in published maps and institutional affiliations.

\section{Author details}

Tenter for Health Economics Experiment and Public Policy, School of Public Health, Shandong University; Key Laboratory of Health Economics and Policy Research, NHFPC (Shandong University), Jinan, China. No. 44 Wenhuaxi Road, Lixia District, Jinan 250012, China. ${ }^{2}$ Jun Jing Research Center for Public Health, Medical School, Tsinghua University, Room B408, Beijing 100084, China. ${ }^{3}$ School of Economics and School of Management, Tianjin Normal University, West Bin Shui Avenue, Tianjin 300074, China. ${ }^{4}$ TOP Education Institute 1 Central Avenue Australian Technology Park, Eveleigh, Sydney, NSW 2015, Australia. ${ }^{5}$ Research Institute of International Strategies,

Guangdong University of Foreign Studies, Baiyun Avenue North, Guangzhou 510420, People's Republic of China. ${ }^{6}$ Newcastle Business School, University of Newcastle, University Drive, Newcastle, NSW, Australia. ${ }^{7}$ Dong Fureng Institute of Economic and Social Development, Wuhan University, 54 Dongsi Lishi Hutong, Beijing 100010, China.

Received: 27 August 2018 Accepted: 9 May 2019

Published online: 23 May 2019

\section{References}

1. China yearbook of health and family planning. 2015. http://www. chinayearbook.com/yearbook/item/1/195236.html .Accessed 1st Sep 2015.

2. Jason $\mathrm{H}$. Experts debate if the cost of end-of-life cancer care is too high. HemOnc Today www.healio.com Accessed 10th Sep 2010.

3. Laudicella M, Walsh B, Burns $E$, Smith PC. Cost of care for cancer patients in England: evidence from population-based patient-level data. Br J Cancer. 2016;114:1286-9.

4. Xu K, Evans DB, Kawabata K, et al. Household catastrophic health expenditure: a multicountry analysis. Lancet. 2003;362:111-7.

5. Tian MY, Cui D, Zhang YX, Yin X, Fang X, Hu JL. Three kinds of targeted anti-tumor drugs affordable evaluation - Hubei province China. Pharmacy. 2017;28:2746-9 in Chinese.

6. Kavosi Z, Rashidian A, Pourreza A, et al. Inequality in household catastrophic health care expenditure in a low-income society of Iran. Health Policy Plan. 2012;27:613-23.

7. Guan XD, Li H, Xin XX, Guo ZG, Ma LL, Han S, Shi LW. Research on equity and influential factors of medicine expenditure affordability for diabetes patients in China. China Pharmacy. 2015;29:1047-54 in Chinese

8. Sun J, Liabsuetrakul T, Fan Y. Protecting patients with cardiovascular diseases from catastrophic health expenditure and impoverishment by health finance reform. Tropical Med Int Health. 2015;20:1846-54.

9. Wu LN, Fang Y, Yang CJ, Shen Q, Chang J, Zhu WW, et al. Tracking study on affordability of antihypertensive drugs in Shaanxi Province. Chin Pharma. 2016:30:564-9 in Chinese.

10. Chen SQ, Pan Y, He LY, Dong K, Yao L, Xiang L. The analysis of medical security of schizophrenics in a City. Chin Health Econ. 2013;32:58-60 (in Chinese).

11. Li $Y, W u ~ Q, X u L$, Legge D, Hao Y, Gao L, et al. Factors affecting catastrophic health expenditure and impoverishment from medical expenses in China: policy implications of universal health insurance. Bull World Health Organ. 2012;90:729-50.

12. Yu C. Evaluation of medical service level in different regions in China based on the method of factor analysis and cluster analysis. Economic Vision. 2011:12:48-52 in Chinese.

13. Alkhatib AA, Hilden K, Adler DG. Impact of the policy of expanding benefit coverage for cancer patients on catastrophic health expenditure across different income groups in South Korea. Soc Sci Med. 2015;138:241-7.

14. Yardim MS, Cilingiroglu N, Yardim N. Catastrophic health expenditure and impoverishment in Turkey. Health Policy. 2010;94:26-33.

15. Kimman M, Jan S, Yip CH, Thabrany H, Peters SA, Bhoo-Pathy N, et al. Catastrophic health expenditure and 12-month mortality associated with cancer in Southeast Asia: results from a longitudinal study in eight countries. BMC Med. 2015;13:1-11.

16. Su TT, Kouyaté B, Flessa S. Catastrophic household expenditure for health care in a low-income society: a study from Nouna district, Burkina Faso. Bull World Health Organ. 2006;84:21-7.

17. Sylvie B, Mohammad AZ, Jérôme B, et al. Does HIV services decentralization protect against the risk of catastrophic health expenditures? Some lessons from Cameroon. Health Serv Res. 2011:46:2029-56.

18. Kent R, Wim VD, Bart C, Narayanan D, Patrick VD. Indian community health insurance schemes provide partial protection against catastrophic health expenditure. BMC Health Serv Res. 2007;7:43. 
19. Galã RO, Sosa-Rubã SG, Salinas A, et al. Health insurance for the poor: impact on catastrophic and out-of-pocket health expenditures in Mexico. Eur J Health Econ. 2010;11:437-47.

20. Kim Y, Yang B. Relationship between catastrophic health expenditures and household incomes and expenditure patterns in South Korea. Health Policy. 2011;100:239-46.

21. Zhou Z, Gao J. Study of catastrophic health expenditure in china's basic health insurance. Healthmed. 2011;5:1498-507.

22. Kien VD, Minh HV, Giang KB, et al. Socioeconomic inequalities in catastrophic health expenditure and impoverishment associated with non-communicable diseases in urban Hanoi, Vietnam. Int J Equity Health. 2016;15:169.

23. Xie Y, Yongai J. Household wealth in China. Chin Sociol Rev. 2015;47: 203-29 in Chinese.

24. China yearbook of health and family planning. 2015. http://www. chinayearbook.com/yearbook/item/1/195236.html. Accessed 1st Sep 2015.

25. Heckathorn DD. Respondent-driven sampling II:deriving valid population estimates from chain-referral samples of hidden populations. Soc Probl. 2002;49:11-34

26. Heckathorn DD. Respondent-driven sampling: a new approach to the study of hidden populations. Soc Probl. 1997;44:174-99.

27. Salganik MJ, Heckathorn DD. Sampling and estimation in hidden populations using respondent-driven sampling. Sociol Methodol. 2004;34(1):193-240.

28. Qiu PY, Yang Y, Yuan P, et al. Application of respondent-driven sampling in epidemiological studies. Modern Prev Med. 2009;36:4401-3 in Chinese.

29. Weil A. Drug, Set, and Setting: The Basis for Controlled Intoxicant Use[J]. J Psychedelic Drugs. 1984;16(3):1

30. Chen W, Zheng R, Baade PD, et al. Cancer statistics in China, 2015. CA Cancer J Clin. 2016;66(2):115-32.

31. Kavalieratos D, Corbelli J, Zhang D, et al. Association between palliative care and patient and caregiver outcomes: a systematic review and meta-analysis. Jama. 2016;316(20):2104.

32. Azzani M, Yahya A, Roslani AC, et al. Catastrophic health expenditure among colorectal Cancer patients and families: a case of Malaysia. Asia Pac J Public Health. 2017;29:485-94.

33. Xu K. Distribution of health payments and catastrophic expenditures methodology. Geneva: Department of Health System Financing, World Health Organization; 2005.

34. The State Council Leading Group Office of Poverty Alleviation and Development, The increased poverty alleviation standard has greatly benefited hundreds of millions of low-income people. http://www.cpad. gov.cn/art/2012/6/25/art_624_15871.html, Accepted from 25th June, 2012.

35. Chen ZS, Yu T. Poverty line, poverty rate and problems in urban area of China. Compar Econ Soc Syst. 2017;6:40-53.

36. Choi JW, Cho KH, Choi Y, et al. Changes in economic status of households associated with catastrophic health expenditures for cancer in South Korea. Asian Pac J Cancer Prev. 2014;15:2713-7.

37. Zhang $X$, Wu $Q$, Shao $Y$, et al. Socioeconomic inequities in health care utilization in China. Asia Pac J Public Health. 2015;27(4):429-38.

38. Yip WC-M, Hsiao WC, Chen W, Hu S, Ma J, Maynard A. Early appraisal of China's huge and complex health-care reforms. Lancet. 2012;379:833-42.

39. The CPC central committee and the state council. Outline of "healthy China 2030". http://www.nhfpc.gov.cn/guihuaxxs/s3586s/201610/ 21d120c917284007ad9c7aa8e9634bb4.shtml. 2016

40. National Hospice and palliative care organization. Facts and figures: hospice Care in America. 2016. https://www.nhpco.org/sites/default/files/ public/2016_Facts_Figures.pdf.

41. Finance Divsions, Guidance on the implementation of the healthy poverty alleviation project. 2016. http://www.nhfpc.gov.cn/caiwusi/s7785/201606/ d16de85e75644074843142dbc207f65d.shtml.

Ready to submit your research? Choose BMC and benefit from:

- fast, convenient online submission

- thorough peer review by experienced researchers in your field

- rapid publication on acceptance

- support for research data, including large and complex data types

- gold Open Access which fosters wider collaboration and increased citations

- maximum visibility for your research: over $100 \mathrm{M}$ website views per year

At BMC, research is always in progress.

Learn more biomedcentral.com/submissions 